\title{
Cost-effectiveness and safety of the molecular targeted drugs afatinib, gefitinib and erlotinib as first-line treatments for patients with advanced EGFR mutation-positive non-small-cell lung cancer
}

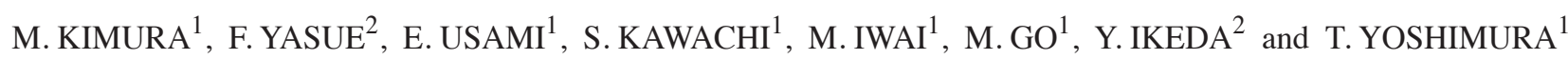 \\ ${ }^{1}$ Department of Pharmacy, Ogaki Municipal Hospital, Ogaki-shi, Gifu 503-8502; ${ }^{2}$ Faculty of \\ Pharmaceutical Sciences, Kinjo Gakuin University, Nagoya-shi, Aichi 463-8521, Japan
}

Received February 22, 2018; Accepted May 29, 2018

DOI: $10.3892 / \mathrm{mco} .2018 .1640$

\begin{abstract}
Epidermal growth factor receptor-tyrosine kinase inhibitors (EGFR-TKIs), including gefitinib, erlotinib and afatinib are standard first-line treatments for EGFR gene mutation-positive non-small cell lung cancer. The present study aimed to compare the cost-effectiveness of using erlotinib, afatinib or gefitinib. The safety of EGFR-TKIs was also investigated. Expected costs were calculated based on data from patients with advanced EGFR mutation-positive non-small-cell lung cancer who were treated with gefitinib, erlotinib or afatinib. Literature was collected to obtain the necessary clinical information for calculating the probability and the validity of each chemotherapy. Median survival time (MST) was used to evaluate the therapeutic effect of the regimens. The cost-effectiveness ratio was calculated using expected costs and MSTs for the three regimens. The cost-effectiveness ratio per month was JPY 386,859.4/MST for afatinib, JPY 264,788.7/MST for gefitinib and JPY 397,039.9/MST for erlotinib. Significant differences were observed between the three groups $(\mathrm{p}<0.001)$. The incremental cost-effectiveness ratio (ICER) of gefitinib compared with afatinib per month was JPY 122,070.7/MST. The ICER of gefitinib compared with erlotinib was JPY -69,605.9/MST. Adverse effects of Grade 3 and higher, including diarrhoea (28.6\%) and paronychia (14.3\%) were observed in the afatinib treatment group. Paronychia $(23.1 \%)$ was observed in the erlotinib treatment group, while none were observed in the gefitinib treatment group. These findings demonstrate that gefitinib is more cost effective in comparison with the afatinib and erlotinib regimens, although the afatinib and erlotinib regimens were well-tolerated and produce sufficient effects.
\end{abstract}

Correspondence to: Mr. M. Kimura, Department of Pharmacy, Ogaki Municipal Hospital, 4-86 Minaminokawa-cho, Ogaki-shi, Gifu 503-8502, Japan

E-mail:kimkim0305nao@yahoo.co.jp

Key words: afatinib, gefitinib, erlotinib, cost-effectiveness, adverse event, non-small-cell lung cancer

\section{Introduction}

In recent years, significant progress has been observed in non-small-cell lung cancer chemotherapies. The median survival time (MST) of patients in a phase III clinical trial that compared four platinum-based combination regimens was $~ 1$ year (1). Meanwhile, the MST of patients with EGFR mutation-positive non-small cell lung cancer who were treated with epidermal growth factor receptor-tyrosine kinase inhibitors (EGFR-TKIs) is $\sim 2-3$ years, and such patients show marked improvements (2-10). Following EGFR-TKI therapy, molecular targeted therapeutic agents, such as anaplastic lymphoma kinase (ALK) inhibitors, have been introduced into clinical settings and improve the prognosis of advanced non-small cell lung cancer (11). Furthermore, nivolumab, an immune checkpoint inhibitor, has been adapted and expanded to advanced non-small cell lung cancer therapies $(12,13)$. Thus, dramatic changes have been taking place in the treatment of lung cancer.

EGFR-TKIs include gefitinib, erlotinib, and afatinib and have shown significant improvements in prolonging progression-free survival (PFS) compared to platinum drug combination therapies $(2,3)$. Currently, according to lung cancer clinical practice guidelines (14) for patients with EGFR gene-mutated advanced non-small cell lung cancer who present performance status (PS) scores of 0-1 and are under 75 years of age, it is recommended to perform therapy with either gefitinib, erlotinib, or afatinib as primary treatment. Gefitinib and erlotinib are considered first generation treatments, and afatinib is considered a second generation medication. Meanwhile, each EGFR-TKI has characteristic adverse events (AEs), which primarily include diarrhoea, skin disorders, liver dysfunction, and other conditions. However, the frequency and severity of the AEs associated with each EGFR-TKI are different (2-10). The use of the molecular targeted drugs is expensive, and the high medical cost associated with these treatments has often been discussed (15). Therefore, it is important to use the concept of drug economics, which is popular in western countries, for reducing medical expenses. As represented by the guideline of the National Institute for Health and Clinical Excellence and the Canadian Agency for Drugs and Technologies in Health, economic evaluations have 


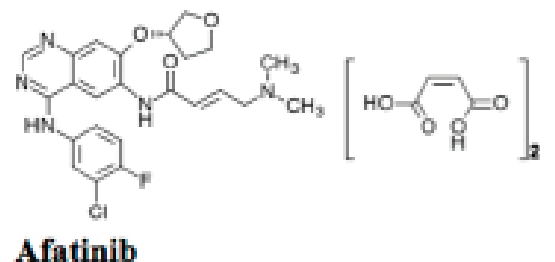

Afatinib

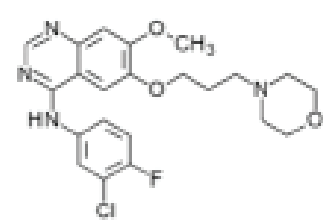

Gefitinib

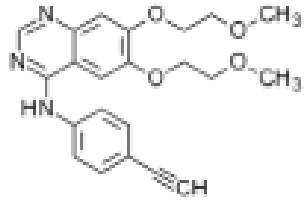

Erlotinib

Figure 1. Chemical schemes of each epidermal growth factor receptor-tyrosine kinase inhibitors (EGFR-TKI).

already been mandated in the US and European countries (16). However, few cost-benefit analyses of advanced EGFR mutation-positive non-small-cell lung cancer chemotherapies have been reported (17).

In this study, we evaluated the economic superiority of afatinib to gefitinib and erlotinib as treatments for patients with advanced EGFR mutation-positive non-small-cell lung cancer. In addition, we investigated the safety of each EGFR-TKI (Fig. 1).

\section{Patients and methods}

Treatment regimens. Afatinib was orally administered once a day at $40 \mathrm{mg}$ on an empty stomach. Gefitinib was orally administered at $250 \mathrm{mg}$ once a day. Erlotinib was administered orally, once a day 1 hour or more before a meal or $2 \mathrm{~h}$ after a meal.

Cost-effectiveness analysis. For non-small cell lung cancer, data from patients who received afatinib, gefitinib, or erlotinib chemotherapy between August 2014 and August $2017(n=142)$ were extracted from electronic medical records. Patients who were administered the abovementioned chemotherapy after second line therapy $(n=56)$ with a PS score of $\geq 2$ and those aged 75 years or older $(n=45)$ were excluded (Fig. 2$)$. A total of 41 patients were included in the study.

Cost data. Cost data includes direct costs incurred at the time of chemotherapy. Fees for medications (including supportive care), inspections, and outpatient medical examinations were calculated. We collected information about drug prices from the Insurance Drug Encyclopedia (18) and medical fees from the Medical Fee Points Table (19) to calculate total medical expenses. The average medical cost per course was calculated from the actual patient data, and we simulated cost up to the MST.

Calculation exclusions. The diagnostic imaging (chest CT-scan) costs and the labour costs of medical staff are included for each chemotherapy treatment. We excluded these costs from the calculations in this analysis. We also excluded the running and depreciation costs of facilities because they are difficult to dispense on a per patient basis.

Data source of therapeutic effect. A literature review was performed to obtain clinical information for calculating the efficacy probability of each chemotherapy. The search was performed as of October 2017, using PubMed as a document retrieval system. The search used keywords including, 'afatinib',

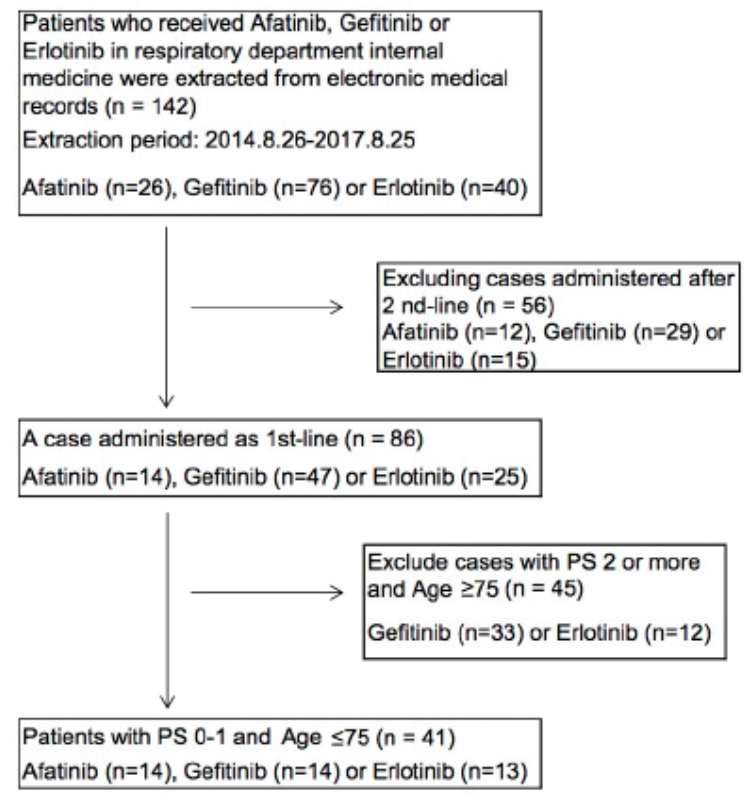

Figure 2. Subject selection and the number of subjects analysed. Exclusion was based on lung cancer clinical practice guidelines.

'gefitinib', 'erlotinib', and 'non-small-cell lung cancer', and was narrowed down to include randomized controlled trials. Cost-effectiveness: The cost-effectiveness analysis was conducted by examining the cost and effectiveness data of each chemotherapy identified through the above methods. The cost-effectiveness ratio of each chemotherapy was calculated by dividing the expected cost by the MST. In addition, the incremental cost-effectiveness ratio (ICER) was used to examine the superiority of the gefitinib versus the afatinib or erlotinib using the following equation: i) ICER (JPY/MST) $=$ (expected cost of afatinib-expected cost of gefitinib)/(MST of afatinib-MST of gefitinib); ii) ICER (JPY/MST) = (expected cost of erlotinib-expected cost of gefitinib)/(MST of erlotinib-MST of gefitinib)

$A E$ analysis. AEs were retrospectively investigated for each patient. The date for each AE was identified using electronic charts and pharmacy service records. The severities of AEs were classified according to the Common Terminology Criteria for Adverse Events (20).

Statistical analysis. One-way ANOVA was used to analyse the patient characteristics shown in Table I. One-way ANOVA and Fisher's protected least significant difference (Fisher's PLSD) was used to analyse the variables shown in Tables II and III. 
Table I. Patient characteristics

\begin{tabular}{|c|c|c|c|c|}
\hline Variable & Afatinib & Gefitinib & Erlotinib & P-value \\
\hline Number & 14 & 14 & 13 & \\
\hline \multicolumn{5}{|l|}{ Age, years } \\
\hline Median (range) & $64(52-75)$ & $71(44-75)$ & $69(59-74)$ & $0.212^{\mathrm{a}}$ \\
\hline \multicolumn{5}{|l|}{ Sex, $n$} \\
\hline Male/female & $6 / 8$ & $6 / 8$ & $8 / 5$ & $0.173^{\mathrm{b}}$ \\
\hline \multicolumn{5}{|l|}{ ECOG performance status } \\
\hline 0 & 7 & 8 & 9 & $0.155^{\mathrm{b}}$ \\
\hline 1 & 7 & 6 & 4 & \\
\hline \multicolumn{5}{|l|}{$\mathrm{Alb}, \mathrm{g} / \mathrm{dl}$} \\
\hline Median (range) & $3.9(3.4-4.7)$ & $4.1(3.3-4.8)$ & $4.1(3.2-4.7)$ & $0.908^{c}$ \\
\hline \multicolumn{5}{|l|}{ Body surface area, $\mathrm{m}^{2}$} \\
\hline Median (range) & $1.65(1.44-1.92)$ & $1.49(1.20-1.77)$ & $1.53(1.29-1.72)$ & $0.015^{\mathrm{a}}$ \\
\hline \multicolumn{5}{|l|}{$\mathrm{CrCl}, \mathrm{ml} / \mathrm{min}$} \\
\hline Median (range) & $76.3(46.4-151.1)$ & $59.4(43.3-131.2)$ & $61.6(22.3-93.3)$ & $0.073^{\mathrm{a}}$ \\
\hline \multicolumn{5}{|l|}{ Disease status } \\
\hline Unresectable & 15 & 9 & 10 & $0.293^{b}$ \\
\hline Recurrent & 0 & 5 & 3 & \\
\hline \multicolumn{5}{|l|}{ Metastatic site } \\
\hline Lymph node & 8 & 8 & 5 & $0.397^{\mathrm{b}}$ \\
\hline Pleural dissemination & 3 & 5 & 2 & \\
\hline Liver & 4 & 1 & 2 & \\
\hline Bone & 6 & 5 & 6 & \\
\hline Brain & 5 & 0 & 8 & \\
\hline Others & 2 & 0 & 1 & \\
\hline
\end{tabular}

a One-factor ANOVA, ${ }^{\mathrm{b}} \mathrm{Chi}$-square for independence test and ${ }^{\mathrm{c} F i s h e r ' s ~ P L S D ~(a f a t i n i b ~ v s . ~ g e f i t i n i b ; ~} \mathrm{p}=0.005$; afatinib vs. erlotinib; $\mathrm{p}=0.051$, gefitinib vs. erlotinib; $\mathrm{p}=0.354$ ). Fisher's PLSD,Fisher's protected least significant difference; $\mathrm{CrCl}$, creatinine clearance; Alb, serum albumin value.

Table II. Cost data (JPY).

\begin{tabular}{|c|c|c|c|c|}
\hline Variable & Afatinib & Gefitinib & Erlotinib & P-value \\
\hline \multicolumn{5}{|l|}{ Medication fee } \\
\hline Anticancer drugs & $302,898.3$ & $197,246.2$ & $294,893.1$ & $<0.001^{\mathrm{a}}$ \\
\hline Supportive care drugs & $16,998.9$ & $8,631.9$ & $24,554.9$ & 0.110 \\
\hline Inspection fee & $4,965.2$ & $5,499.2$ & $6,376.8$ & 0.539 \\
\hline Outpatient medical examination fee & $8,523.8$ & $5,021.0$ & $7,737.1$ & $0.012^{\mathrm{b}}$ \\
\hline Hospitalization expense & $52,294.7$ & $43,221.7$ & $52,294.7$ & $0.004^{\mathrm{c}}$ \\
\hline Others & $6,151.9$ & $5,168.7$ & $11,183.3$ & 0.368 \\
\hline Total & $391,832.8$ & $264,788.7$ & $397,039.9$ & $<0.001^{\mathrm{d}}$ \\
\hline
\end{tabular}

In all significance tests, $\mathrm{p}$-values $<0.05$ were considered to indicate statistical significance. All statistical analyses were performed with EZR (v1.30, Saitama Medical Center, Jichi
Medical University, Saitama, Japan), which is a graphical user interface for R (The R Foundation for Statistical Computing, Vienna, Austria) (21). 
Table III. Cost-effectiveness ratios.

\begin{tabular}{lccc}
\hline Variable & Expected cost (JPY/person) & Cost-effectiveness ratio ${ }^{\mathrm{a}}(\mathrm{JPY} / \mathrm{MST})$ & MST $(\mathrm{months})$ \\
\hline Afatinib & $9,942,286.8$ & $386,859.4$ & 25.7 \\
Gefitinib & $6,540,280.3$ & $264,788.7$ & 24.7 \\
Erlotinib & $9,052,508.9$ & $397,039.9$ & 22.8 \\
P-value & $<0.001^{\mathrm{b}}$ & $<0.001^{\mathrm{c}}$ & 0.892 \\
\hline
\end{tabular}

${ }^{a}$ Cost-effectiveness ratio is defined as the expected cost per person/the effectiveness determined by the MST. ${ }^{b}$ Fisher's PLSD (afatinib vs. gefitinib; $p<0.001$, afatinib vs. erlotinib; $\mathrm{p}=0.027$, gefitinib vs. erlotinib; $\mathrm{p}<0.001$ ). ${ }^{\mathrm{c}}$ Fisher's PLSD (afatinib vs. gefitinib; $\mathrm{p}<0.001$, afatinib vs. erlotinib; $\mathrm{p}=0.510$, gefitinib vs. erlotinib; $\mathrm{p}<0.001$ ). MST, median survival time; PLSD, Protected Least Significant Difference.

Ethical considerations. Personal information was protected in the aggregated data. This study was approved by the Institutional Review Board of Ogaki Municipal Hospital, Ogaki, Japan.

\section{Results}

Patient characteristics. The patient characteristics are summarized in Table I. The median age of patients who received afatinib, gefitinib, and erlotinib was 64 years (range, 52-76), 71 years (range, 44-75), and 69 years (range, 59-74), respectively, and body surface areas were 1.65 (1.44-1.92), 1.49 (1.20-1.77) and $1.53(1.29-1.72)$, respectively.

Cost data. For afatinib, the calculated direct medical costs included medication fees (anticancer drugs $=$ JPY 302,898.3, supportive care drugs = JPY 16,998.9), inspection fees of JPY 4,965.2, outpatient medical examination fees of JPY 8,523.8, and hospitalization fees of JPY 52,294.7. For gefitinib, the calculated direct medical costs included medication fees (anticancer drugs = JPY 197,246.2 supportive care drugs = JPY $8,631.9$ ), inspection fees of JPY 5,499.2, outpatient fees of JPY $5,021.0$, and hospitalization fees of JPY 43,221.7. For erlotinib, the calculated direct medical costs included medication fees (anticancer drugs = JPY 294,893.1, supportive care drugs = JPY 24,554.9), inspection fees of JPY 6,376.8, outpatient medical examination fees of JPY 7,737.1, and hospitalization fees of JPY $52,294.7$. We found that gefitinib were more inexpensive than other regimens, with respect to each medical expense (Table II).

Cost-effectiveness analysis. The cost-effectiveness ratio per month was JPY $386,859.4 /$ MST for afatinib, JPY 264,788.7/MST for gefitinib, and JPY 397,039.9/MST for erlotinib. We found significant differences between the three groups (Table III; $\mathrm{p}<0.001$ ). The ICER ratio per month of gefitinib to afatinib was JPY $122,070.7 /$ MST. The ICER of gefitinib to erlotinib was JPY -69,605.9/MST.

AE analysis. The major AEs are summarized in Table IV. For afatinib, AEs included diarrhoea (92.9\%), rash $(71.4 \%)$, oral mucositis $(71.4 \%)$, and increased alanine aminotransferase (ALT) levels $(50.0 \%)$. For gefitinib, rash (64.3\%), aspartate aminotransferase/ALT increases (57.1\%), anaemia (42.9\%), and diarrhoea (35.7\%) were observed. For erlotinib, anorexia (84.6\%), nausea (84.6\%), rash (76.9\%), and leucopenia (53.8\%) occurred.

\section{Discussion}

In this study, we conducted a drug-economic analysis to compare afatinib, gefitinib, and erlotinib for first-line treatment of patients with advanced EGFR mutation-positive non-small-cell lung cancer. In addition, we investigated the safety of afatinib, gefitinib, and erlotinib.

We found that the cost-effectiveness of gefitinib achieved better results than both afatinib and erlotinib. In implementing gefitinib, total expenses such as anticancer drug costs, outpatient fees, and hospitalization fees were lower than for afatinib and erlotinib. Notably, we found that the cost of anticancer drugs greatly affects the total cost. However, the cost data in this study are based on the patient population of a single facility. In the future, if cost data are collected from several facilities, the data can be applied more widely. In terms of therapeutic effects, there are no direct comparison tests of the three EGFR-TKIs. In the current data, there is a possibility that the therapeutic effects of afatinib, gefitinib, and erlotinib may be expected in order (2-10). In this study, the effect of EGFR-TKIs is not different between the three therapeutics (afatinib, erlotinib, and gefitinib), as defined by MST in various phase III trials.

According to a survey conducted by Shiroiwa et al (22). and Ohkusa et al (23), <500-6 million yen per qualityadjusted life year (QALY) is considered cost effective. As this study does not consider patient quality of life, it is impossible to accurately determine cost-effectiveness. However, since the ICER of gefitinib versus afatinib or erlotinib were JPY 122,070.7/MST and JPY -69,605.9/MST, respectively, gefitinib are relatively lower cost than afatinib and erlotinib in terms of medical expenses, and we assumed that this is within a good range in terms of cost effectiveness. Through comparing the cost-effectiveness of erlotinib, afatinib, and cisplatin plus pemetrexed, we observed that both TKIs were more cost-effective than cisplatin-pemetrexed (17). Erlotinib had an ICER of \$61,809/QALY compared with afatinib. Ting et al reported that erlotinib is the preferred first-line treatment for advanced epithelial growth factor receptor mutation-positive non-small-cell lung cancer (17). Meanwhile, in this study, there was no difference between erlotinib and afatinib. 
Table IV. Adverse events for each drug regimen.

\begin{tabular}{|c|c|c|c|c|c|c|c|c|c|c|c|c|}
\hline \multirow[b]{3}{*}{ Adverse event } & \multicolumn{4}{|c|}{ Afatinib $(n=14)$} & \multicolumn{4}{|c|}{ Gefitinib $(n=14)$} & \multicolumn{4}{|c|}{ Erlotinib $(n=13)$} \\
\hline & \multicolumn{3}{|c|}{ Grade } & \multirow[b]{2}{*}{ All grades $(\%)$} & \multicolumn{3}{|c|}{ Grade } & \multirow[b]{2}{*}{ All grades $(\%)$} & \multicolumn{3}{|c|}{ Grade } & \multirow[b]{2}{*}{ All grades $(\%)$} \\
\hline & 1 & 2 & $\leq 3$ & & 1 & 2 & $\leq 3$ & & 1 & 2 & $\leq 3$ & \\
\hline Leucopenia & 2 & 0 & 0 & $2(14.3)$ & 2 & 1 & 1 & $4(28.6)$ & 3 & 4 & 0 & $7(53.8)$ \\
\hline Neutropenia & 0 & 0 & 0 & $0(0)$ & 2 & 0 & 1 & $3(21.4)$ & 4 & 0 & 0 & $4(30.8)$ \\
\hline Platelet count decreased & 0 & 0 & 0 & $0(0)$ & 1 & 0 & 0 & $1(7.1)$ & 2 & 0 & 0 & $2(15.4)$ \\
\hline Anaemia & 0 & 0 & 0 & $0(0)$ & 3 & 2 & 1 & $6(42.9)$ & 3 & 1 & 0 & $4(30.8)$ \\
\hline AST increased & 3 & 2 & 0 & $5(35.7)$ & 6 & 1 & 1 & $8(57.1)$ & 2 & 1 & 0 & $3(23.1)$ \\
\hline ALT increased & 3 & 2 & 1 & $6(42.9)$ & 6 & 1 & 1 & $8(57.1)$ & 3 & 1 & 1 & $5(38.5)$ \\
\hline Blood bilirubin increased & 0 & 0 & 0 & $0(0)$ & 1 & 0 & 0 & $1(7.1)$ & 3 & 1 & 0 & $4(30.8)$ \\
\hline Creatinine increased & 0 & 4 & 0 & $4(28.6)$ & 3 & 1 & 0 & $4(28.6)$ & 1 & 3 & 0 & $4(30.8)$ \\
\hline Fatigue & 3 & 0 & 0 & $3(21.4)$ & 2 & 0 & 0 & $2(14.3)$ & 3 & 0 & 0 & $3(23.1)$ \\
\hline Anorexia & 3 & 0 & 0 & $3(21.4)$ & 2 & 1 & 0 & $3(21.4)$ & 9 & 1 & 1 & $11(84.6)$ \\
\hline Nausea & 5 & 1 & 0 & $6(42.9)$ & 1 & 0 & 0 & $1(7.1)$ & 9 & 1 & 1 & $11(84.6)$ \\
\hline Vomiting & 2 & 0 & 0 & $2(14.3)$ & 0 & 0 & 0 & $0(0)$ & 0 & 0 & 0 & $0(0)$ \\
\hline Mucositis oral & 7 & 3 & 0 & $10(71.4)$ & 4 & 0 & 0 & $4(28.6)$ & 7 & 1 & 0 & $8(61.5)$ \\
\hline Diarrhoea & 6 & 3 & 4 & $13(92.9)$ & 4 & 1 & 0 & $5(35.7)$ & 9 & 0 & 0 & $9(69.2)$ \\
\hline Constipation & 0 & 0 & 0 & $0(0)$ & 2 & 0 & 0 & $2(14.3)$ & 0 & 0 & 0 & $0(0)$ \\
\hline Rash & 7 & 3 & 0 & $10(71.4)$ & 6 & 2 & 1 & $9(64.3)$ & 7 & 2 & 1 & $10(76.9)$ \\
\hline Paronychia & 3 & 1 & 2 & $6(42.9)$ & 0 & 0 & 0 & $0(0)$ & 1 & 3 & 3 & $7(53.8)$ \\
\hline $\begin{array}{l}\text { Palmar-plantar } \\
\text { erythrodysesthesia syndrome }\end{array}$ & 0 & 3 & 0 & $3(21.4)$ & 1 & 0 & 0 & $1(7.1)$ & 0 & 0 & 0 & $0(0)$ \\
\hline Fever & 1 & 0 & 0 & $1(7.1)$ & 2 & 0 & 0 & $2(14.3)$ & 0 & 0 & 0 & $0(0)$ \\
\hline Dysgeusia & 0 & 0 & 0 & $0(0)$ & 1 & 0 & - & $1(7.1)$ & 0 & 0 & 0 & $0(0)$ \\
\hline Neuralgia & 1 & 0 & 0 & $1(7.1)$ & 1 & 0 & 0 & $1(7.1)$ & 1 & 0 & 0 & $1(7.7)$ \\
\hline Others & 5 & 0 & 0 & $5(35.7)$ & 4 & 0 & 0 & $4(28.6)$ & 2 & 0 & 0 & $2(15.4)$ \\
\hline
\end{tabular}

AST, aspartate aminotransferase; ALT, alanine aminotransferase.

The development of AEs varies according to the type of TKI. Each adverse event profile was similar to those observed in previous reports (2-10). Rash toxicity is a common adverse event, but hepatic injury is observed more frequently for gefitinib, anorexia and nausea is more frequent for erlotinib, and diarrhoea is more common for afatinib. Interstitial lung disease (ILD), which is a type of pulmonary toxicity, was not observed in this study. Although the frequency of ILD occurrence is small, it is reported that $\sim 4-5 \%$ cases occur in any TKI therapy and in slightly $<1 \%$, it is lethal (24). Adverse effects of Grade 3 and higher were found in afatinib therapy, including diarrhoea and paronychia, and in erlotinib therapy, including paronychia, but not for gefitinib. Therefore, it can be predicted that AEs are intensified in the order of gefitinib, erlotinib, and afatinib. From the above observations, we consider that the choice of TKI should be determined based on the balance between beneficial effects and AEs.

This study is the first to analyse the cost-effectiveness of three types of molecular targeted drugs for first-line treatment of patients with advanced EGFR mutation-positive non-small-cell lung cancer. Gefitinib is cost effective compared to afatinib and erlotinib, although afatinib and erlotinib are well-tolerated with sufficient effects.

\section{Acknowledgements}

Not applicable.

\section{Funding}

No funding was received.

\section{Availability of data and materials}

The datasets used and/or analyzed during the current study are available from the corresponding author on reasonable request.

\section{Authors' contributions}

MK, FY, EU, SK, MI, MG YI and TY conceived and designed the study. MK and FY acquired the data. MK, FY, EU, SK, MI, MG, YI and TY drafted the manuscript. All authors read and approved the final manuscript. 


\section{Ethics approval and consent to participate}

This study was approved by the Institutional Review Board of Ogaki Municipal Hospital, Ogaki, Japan.

\section{Consent for publication}

Not applicable.

\section{Competing interests}

The authors declare that they have no competing interests.

\section{References}

1. Ohe Y, Ohashi Y, Kubota K, Tamura T, Nakagawa K, Negoro S, Nishiwaki Y, Saijo N, Ariyoshi Y and Fukuoka M: Randomized phase III study of cisplatin plus irinotecan versus carboplatin plus paclitaxel, cisplatin plus gemcitabine, and cisplatin plus vinorelbine for advanced non-small-cell lung cancer: Four-Arm Cooperative Study in Japan. Ann Oncol 18: 317-323, 2007.

2. Maemondo M, Inoue A, Kobayashi K, Sugawara S, Oizumi $\mathrm{S}$, Isobe $\mathrm{H}$, Gemma $\mathrm{A}$, Harada $\mathrm{M}$, Yoshizawa $\mathrm{H}$, Kinoshita I, et al; North-East Japan Study Group: Gefitinib or chemotherapy for non-small-cell lung cancer with mutated EGFR. N Engl J Med 362: 2380-2388, 2010.

3. Mitsudomi T, Morita S, Yatabe Y, Negoro S, Okamoto I, Tsurutani J, Seto T, Satouchi M, Tada H, Hirashima T, et al; West Japan Oncology Group: Gefitinib versus cisplatin plus docetaxel in patients with non-small-cell lung cancer harbouring mutations of the epidermal growth factor receptor (WJTOG3405): An open label, randomised phase 3 trial. Lancet Oncol 11: 121-128, 2010.

4. Rosell R, Carcereny E, Gervais R, Vergnenegre A, Massuti B, Felip E, Palmero R, Garcia-Gomez R, Pallares C, Sanchez JM, et al; Spanish Lung Cancer Group in collaboration with Groupe Français de Pneumo-Cancérologie and Associazione Italiana Oncologia Toracica: Erlotinib versus standard chemotherapy as first-line treatment for European patients with advanced EGFR mutation-positive non-small-cell lung cancer (EURTAC): A multicentre, open-label, randomised phase 3 trial. Lancet Oncol 13: 239-246, 2012.

5. Wu YL, Zhou C, Liam CK, Wu G, Liu X, Zhong Z, Lu S, Cheng Y, Han B, Chen L, et al: First-line erlotinib versus gemcitabine/cisplatin in patients with advanced EGFR mutation-positive non-small-cell lung cancer: Analyses from the phase III, randomized, open-label, ENSURE study. Ann Oncol 26: 1883-1889, 2015.

6. Yang JC, Wu YL, Schuler M, Sebastian M, Popat S, Yamamoto N, Zhou C, Hu CP, O'Byrne K, Feng J, et al: Afatinib versus cisplatin-based chemotherapy for EGFR mutation-positive lung adenocarcinoma (LUX-Lung 3 and LUX-Lung 6): Analysis of overall survival data from two randomised, phase 3 trials. Lancet Oncol 16: 141-151, 2015.

7. Paz-Ares L, Tan EH, O'Byrne K, Zhang L, Hirsh V, Boyer M, Yang JC, Mok T, Lee KH, Lu S, et al: Afatinib versus gefitinib in patients with EGFR mutation-positive advanced non-small-cell lung cancer: Overall survival data from the phase IIb LUX-Lung 7 trial. Ann Oncol 28: 270-277, 2017.

8. Kato T, Yoshioka H, Okamoto I, Yokoyama A, Hida T, Seto T, Kiura K, Massey D, Seki Y and Yamamoto N: Afatinib versus cisplatin plus pemetrexed in Japanese patients with advanced non-small cell lung cancer harboring activating EGFR mutations: Subgroup analysis of LUX-Lung 3. Cancer Sci 106: 1202-1211, 2015.
9. Oizumi S, Kobayashi K, Inoue A, Maemondo M, Sugawara S, Yoshizawa $\mathrm{H}$, Isobe $\mathrm{H}$, Harada M, Kinoshita I, Okinaga S, et al: Quality of life with gefitinib in patients with EGFR-mutated non-small cell lung cancer: Quality of life analysis of North East Japan Study Group 002 Trial. Oncologist 17: 863-870, 2012.

10. Inoue A, Kobayashi K, Maemondo M, Sugawara S, Oizumi S, Isobe $\mathrm{H}$, Gemma A, Harada M, Yoshizawa H, Kinoshita I, et al; North-East Japan Study Group: Updated overall survival results from a randomized phase III trial comparing gefitinib with carboplatin-paclitaxel for chemo-naïve non-small cell lung cancer with sensitive EGFR gene mutations (NEJ002). Ann Oncol 24: 54-59, 2013.

11. Solomon BJ, Mok T, Kim DW, Wu YL, Nakagawa K, Mekhail T, Felip E, Cappuzzo F, Paolini J, Usari T, et al; PROFILE 1014 Investigators: First-line crizotinib versus chemotherapy in ALK-positive lung cancer. N Engl J Med 371: 2167-2177, 2014.

12. Brahmer J, Reckamp KL, Baas P, Crinò L, Eberhardt WE, Poddubskaya E, Antonia S, Pluzanski A, Vokes EE, Holgado E, et al: Nivolumab versus Docetaxel in Advanced Squamous-Cell Non-Small-Cell Lung Cancer. N Engl J Med 373: 123-135, 2015.

13. Borghaei H, Paz-Ares L, Horn L, Spigel DR, Steins M, Ready NE, Chow LQ, Vokes EE, Felip E, Holgado E, et al: Nivolumab versus Docetaxel in Advanced Nonsquamous Non-Small-Cell Lung Cancer. N Engl J Med 373: 1627-1639, 2015.

14. The Japan Lung Cancer Society: https://www.haigan.gr.jp/ modules/guideline/index.php?content_id=3. Accessed April 6, 2018.

15. Meropol NJ, Schrag D, Smith TJ, Mulvey TM, Langdon RM Jr, Blum D, Ubel PA and Schnipper LE; American Society of Clinical Oncology: American Society of Clinical Oncology guidance statement: The cost of cancer care. J Clin Oncol 27: 3868-3874, 2009.

16. Williams I, McIver S, Moore D and Bryan S: The use of economic evaluations in NHS decision-making: A review and empirical investigation. Health Technol Assess 12: iii, ix-x, 1-175, 2008.

17. Ting J, Tien Ho P, Xiang P, Sugay A, Abdel-Sattar M and Wilson L: Cost-Effectiveness and Value of Information of Erlotinib, Afatinib, and Cisplatin-Pemetrexed for First-Line Treatment of Advanced EGFR Mutation-Positive Non-Small-Cell Lung Cancer in the United States. Value Health 18: 774-782, 2015.

18. Pharmaceutical Society: Insurance drug encyclopedia, Jiho. Pharmaceutical Society, Tokyo, 2012.

19. Kawakami Y: Medical fee points table. 35 th edition. Social Insurance Institute, Tokyo, 2008.

20. US Department Of Health And Human Services: Common terminology criteria for adverse events (CTCAE) version 4.0. United States, National Cancer Institute, 2009. https://ctep.cancer.gov/ protocoldevelopment/electronic_applications/ctc.htm\#ctc_40. Accessed April 6, 2018

21. Kanda Y: Investigation of the freely available easy-to-use software 'EZR' for medical statistics. Bone Marrow Transplant 48: 452-458, 2013

22. Shiroiwa T, Sung YK, Fukuda T, Lang HC, Bae SC and Tsutani K: International survey on willingness-to-pay (WTP) for one additional QALY gained: What is the threshold of cost effectiveness? Health Econ 19: 422-437, 2010.

23. Ohkusa Y and Sugawara T: Research for Willingness to Pay for One QALY Gain. Iryo To Shakai 16: 157-165, 2006. (In Japanese).

24. Takeda M, Okamoto I and Nakagawa K: Pooled safety analysis of EGFR-TKI treatment for EGFR mutation-positive non-small cell lung cancer. Lung Cancer 88: 74-79, 2015. 